\title{
Finite Element Analysis and Structure Optimal Design of the Column of Deep-Hole Drilling Machine
}

\author{
Baohui Li \\ College of Mechanical Engineering, University of Shanghai for Science and Technology \\ 516 Jun Gong Road, Shanghai, 200093, China \\ Tel: 86-152-1676-7095Ｅ-mail: leebaohui@163.com \\ Jingfeng Shen \\ College of Mechanical Engineering, University of Shanghai for Science and Technology \\ 516 Jun Gong Road, Shanghai, 200093, China \\ Tel: 86-21-5527-3617Ｅ-mail:sh_jf@163.com \\ Zhidong Zhang \\ College of Mechanical Engineering, University of Shanghai for Science and Technology \\ 516 Jun Gong Road, Shanghai, 200093, China \\ Tel: 86-188-0215-2123 E-mail: 305176534@qq.com
}

Received: June 14, 2011

Accepted: July 22, 2011

doi:10.5539/mas.v5n5p196

Supported by Shanghai Leading Academic Discipline Project (J50503), China National Innovation Funding Project (09C26213103478) and Shanghai Innovation Funding Project (0904h131300)

\begin{abstract}
Solidworks is selected for modeling the 3D-solid structure of the column of the deep-hole drilling machine, as well as solidworks simulation for the analysis of the casting model. For the purpose of optimizing the weight of the column, two parameters (column thickness and inner rib thickness) are included and three optimal design methods are compared in the event that the column stiffness and displacement are under control.
\end{abstract}

Keywords: Deep-hole drilling machine, Column structure, Solid modeling, Finite element analysis

\section{Prefaces}

The displacement of the column is one of the most important factors which affect the accuracy of machining, so displacement limitation becomes very strict to guarantee the precision of the deep holes. Solidworks is adopted in this paper to build the geometric model of the column and solidworks simulation is used for static structure analysis to examine the stress and displacement of the original design, and optimal solution is carried out finally for the sake of reducing the weight of the column.

\section{Mathematical modeling}

\subsection{Geometric model and model simplification}

Casting and machining method is adopted to build the column body. It owns the symmetrical structure and X-style internal ribs are applied to reinforce the column body. The parameters are as follows: Total height 5700mm, length: 1920mm, width: 2100mm,column thickness: 45mm, upper lid thickness: 60mm, lower lid thickness: $154 \mathrm{~mm}$. The geometrical model is shown in figure 1. Geometric model is simplified by feature compression to reduce the computation of meshing geometric model and simplified geometric model is shown in figure 2.

\subsection{Working condition and external load analysis}

Drilling assembly slides along the column sideways from $0 \mathrm{~mm}$ to $3000 \mathrm{~mm}$ under the condition of drilling. Three drilling shafts move simultaneously and the distance between them can be adjusted from $250 \mathrm{~mm}$ to $300 \mathrm{~mm}$. The 
drilling assembly weight is 11 tons and the center-balance counterpart is 11 tons accordingly. Pre-force for fixing the pipe sheet is loaded in advance and drilling reaction force is generated when working. So dangerous working condition appears when the drilling assembly reaches the maximum trip $(3000 \mathrm{~mm})$. The working condition and load are shown in table 1.

Both column and slider asembly are built at first(shown in Fingure3) but during the analysis slider asembly is removed and pre-force and drilling reaction force are substituted by remote load(shown in Figure 4 by yellow arrows).

\subsection{Other options}

"Static analysis" is chosen for the column analysis and the " material property" is HT250. Fixture constraint is "fixed" for the lower part of the column is connected to machine body by 21 bolts.

\section{Finite element analysis model}

Column model is discretized for the purpose of generating FEA model after the establishment of mathematical model. Solidworks simulation provides three units for FEA: beam element unit, shell unit and solid-tetrahedron unit and each unit contains two options: draft quality and advanced quality. Advanced quality solid-tetrahedron unit is chosen in this paper according to the mathematical model built before. FEA model is generated by Solidworks simulation's intelligent grid division technology and is shown in Figure 4.

\section{Run and results analysis}

\subsection{Stress analysis}

Just as shown in Figure 5, von mises stress of the most part of the column is under 11.414Mpa, and the maximum stress is $19.565 \mathrm{Mpa}$ which appears at the position of contention area. The stress conclusion is that the working stress of the column is far more below the yield limitation (tensile strength) 250Mpa.

\subsection{Displacement analysis}

To guarantee the precision of the deep holes, the displacement of the column(X direction) is limited to $0.150 \mathrm{~mm}$. As shown in Figure 6, the displacement of the most part of the column is far more below $0.080 \mathrm{~mm}$ under the circumstances of dangerous working condition and the maximum displacement is $0.125 \mathrm{~mm}$.

\section{Optimization}

As stated previously, the working stress is far more below the yield limitation 250Mpa and the displacement of the column(X direction) is also below the limitation $0.150 \mathrm{~mm}$. So we can come to the conclusion that stiffness design tends to be conservative. Column structure is optimized with three ways as follows.

\subsection{Rib thickness optimization}

Rib thickness is reduced independently from $25 \mathrm{~mm}$ to $12.5 \mathrm{~mm}$ by the step of $2.5 \mathrm{~mm}$ and the column is reanalyzed and shown in Figure 7.The relationship between column weight and rib thickness is shown in figure 8(a) and the relationship between column displacement and rib thickness is shown in figure 8(b).

Just as shown in the line charts, the reduction of rib thickness produces less affection on the column displacement and the reduction of column weight is not obvious(from 24.006 tons to 23.167 tons). The optimized column is $3.49 \%$ lighter than the original design.

\subsection{Column thickness optimization}

Column thickness is reduced independently this time from $45 \mathrm{~mm}$ to $32.5 \mathrm{~mm}$ by the step of $2.5 \mathrm{~mm}$ and the analysis results are shown in figure 9 below. The column weight is $10.23 \%$ lighter and the column displacement rises from $0.125 \mathrm{~mm}$ to $0.145 \mathrm{~mm}$.

\subsection{Comprehensive optimization}

Reduce the rib thickness and column thickness simultaneously by the step of $2.5 \mathrm{~mm}$. As shown in figure 10 , column displacement rises from $0.125 \mathrm{~mm}$ to $0.149 \mathrm{~mm}$ and column weight reduces fast from 24.006 tons to 20.641 tons. Because the displacement value $0.149 \mathrm{~mm}$ is so close to the maximum value $0.150 \mathrm{~mm}, 21.353$ tons(column weight) and $0.143 \mathrm{~mm}$ (column displacement) are adopted for the final optimization design. So the column is $11.05 \%$ lighter than before.

\section{Conclusions}

The work piece used in nuclear power and thermal power industry is made of Mn-Ni-Mo alloy and it is hard to drilling. The column of the deep-hole drilling machine is the most important part for the machining naturally. 
First we examine the original design and then we propose the optimal design. We draw the conclusion that stiffness of the original design tends to be conservative through finite element analysis and column weight is optimized by reducing the rib thickness independently, the column thickness independently and both of them simultaneously. Final optimization solution is obtained through comparing these three methods.

\section{References}

Chen, C. X., \& Ye, X. Z. (2010). Solidworks simulation training manual. (1st ed.).Beijing: China machine press, (Chapter 2).

Chen, C. X., \& Ye, X. Z. (2010). Solidworks essential training manual. (1st ed.). Beijing: China machine press, (Chapter 7).

Wang, Y. J., Shang, J. D., \& Hu, D. F. (2009). Finite Element Analysis of a Column of the NC Machine. Mechanical Engineer, 10, 63-65

Xie, Y. Q., \& He, B. F. (1981). Finite element analysis in theory of elasticity and plasticity. (1st ed.) .Beijing: China machine press, (Chapter 3).

Zhang, X. Y., Xiong, J., Hao, X., \& Lai, R. M. (2008). Column Finite Element Analysis and Structure Optimal Design. Mechanical Science and Technology for Aerospace Engineering, 12, 1602-1605

Zhao, L. F., Wang, Z. H., \& Zhao, X. L. (2010). 3D Modeling and Finite Element Analysis of the Column of the NC Boring Machine. Internal Combustion Engines, 4, 41-43

Table 1. Working conditions

\begin{tabular}{|c|c|c|c|c|}
\hline Pre-force & $\begin{array}{c}\text { Drilling reaction } \\
\text { force }\end{array}$ & $\begin{array}{c}\text { Center-balance } \\
\text { counterpart } \\
\text { weight }\end{array}$ & $\begin{array}{c}\text { Drilling assembly } \\
\text { weight }\end{array}$ & Column weight \\
\hline $147000 \mathrm{~N}$ & $4900 \mathrm{~N}$ & $107800 \mathrm{~N}$ & $107800 \mathrm{~N}$ & $235258.8 \mathrm{~N}$ \\
\hline
\end{tabular}



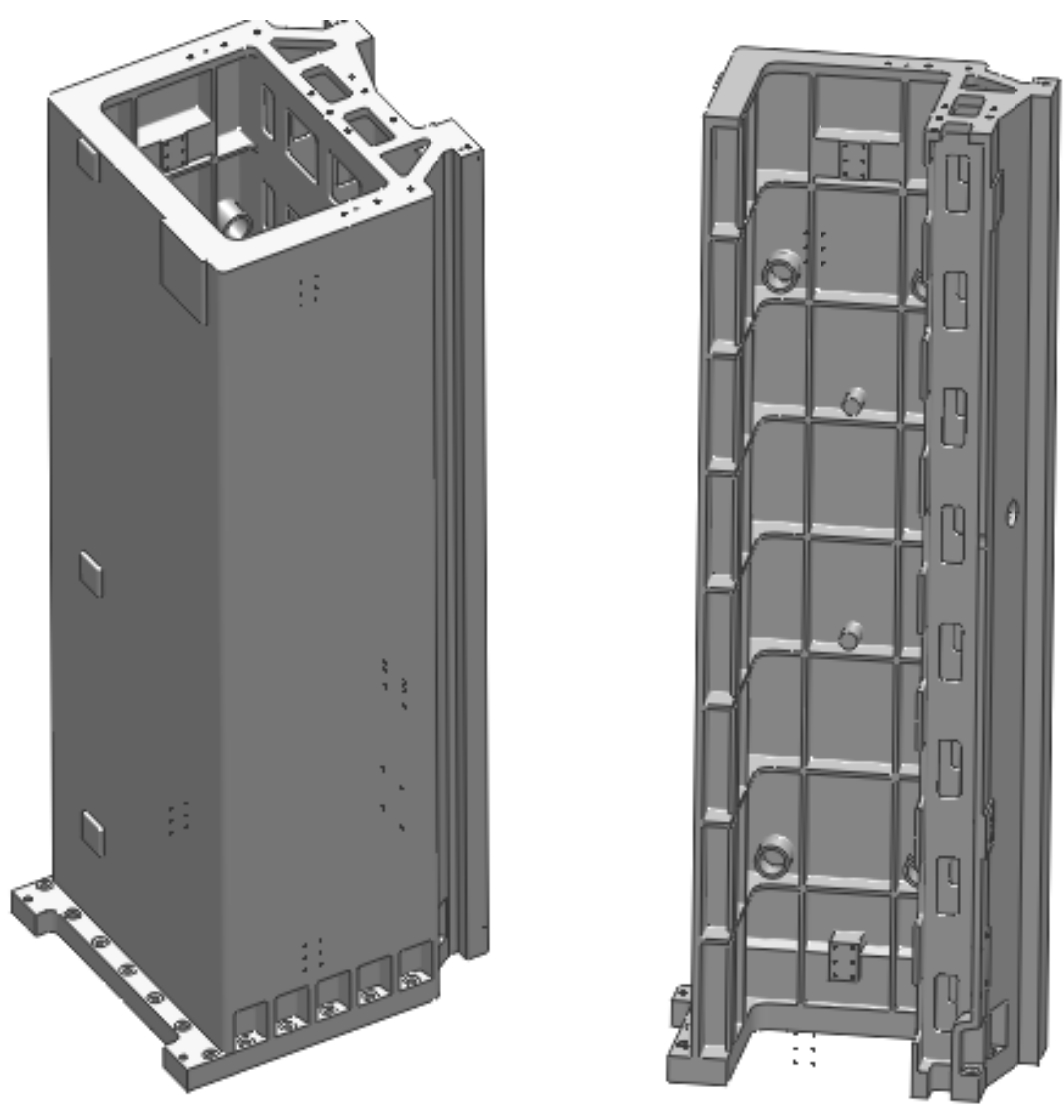

Figure 1. Geometrical model of the column
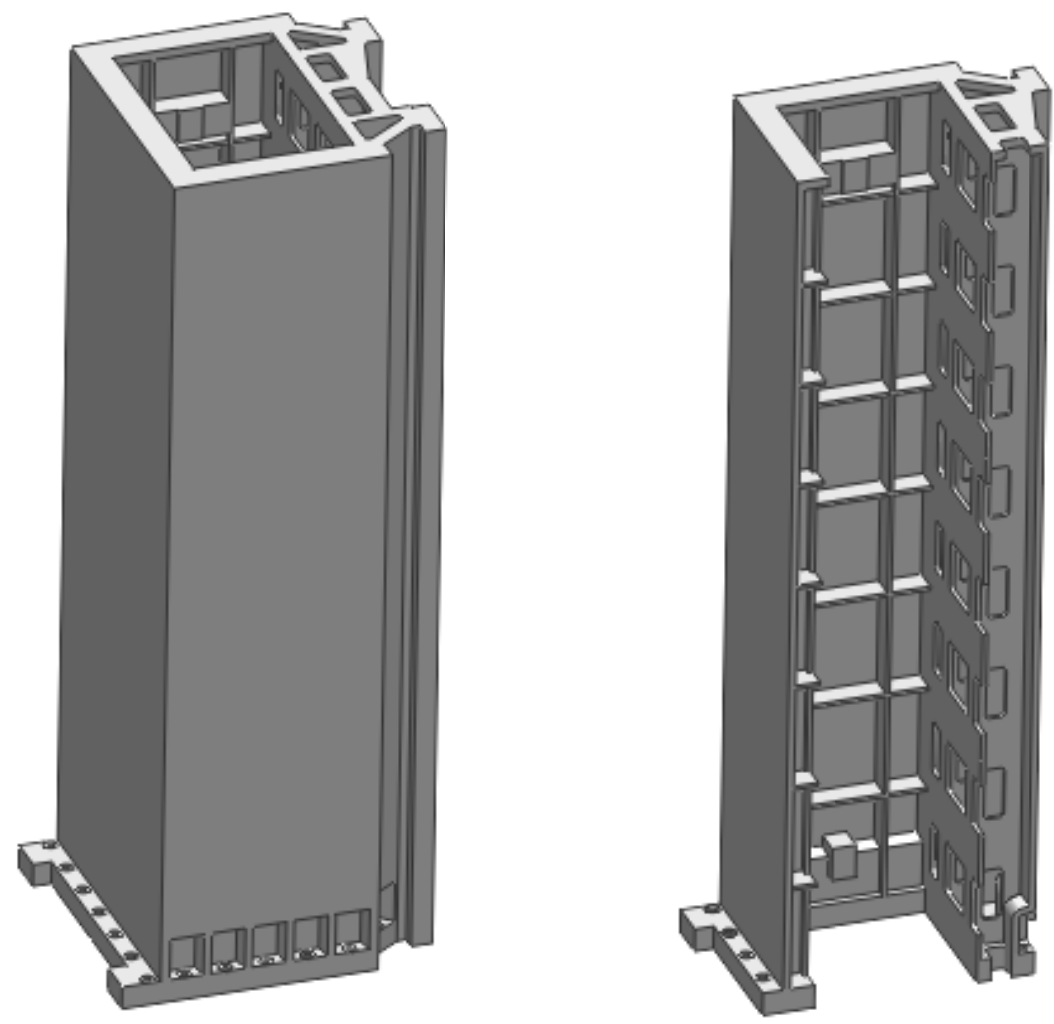

Figure 2. Simplified model 


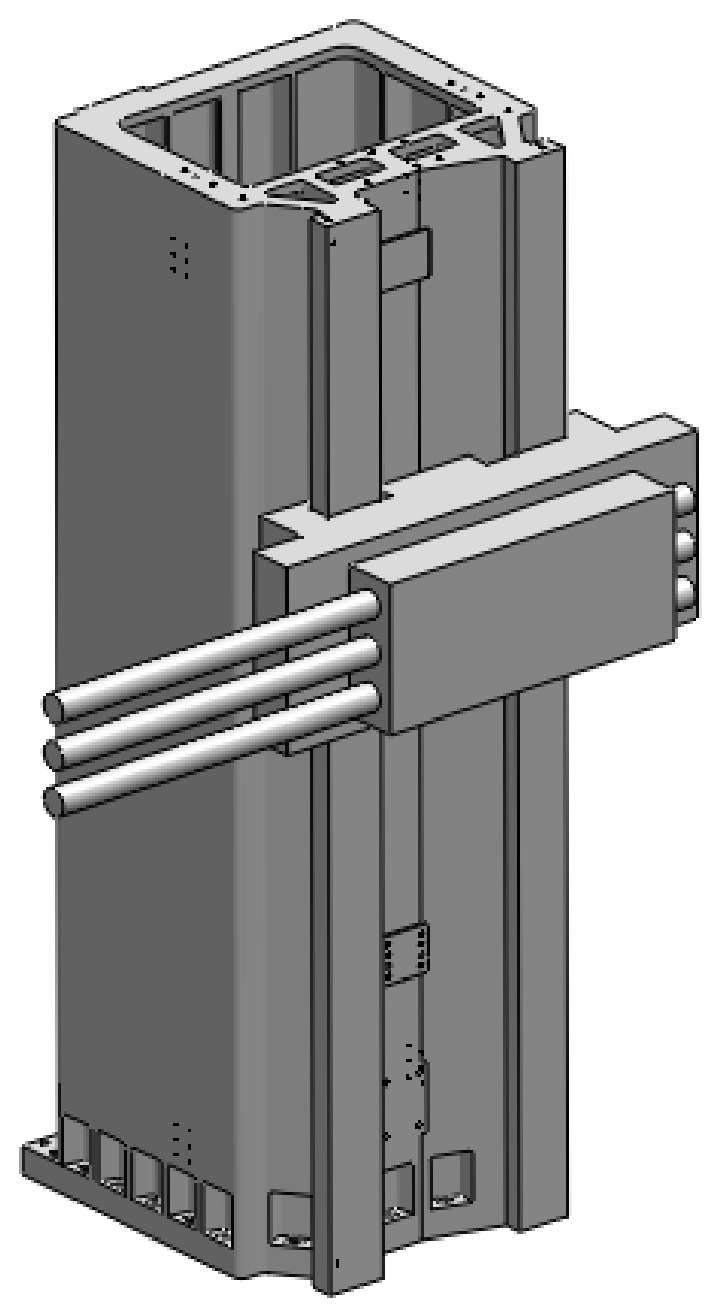

Figure 3. The column and the drilling assembly 

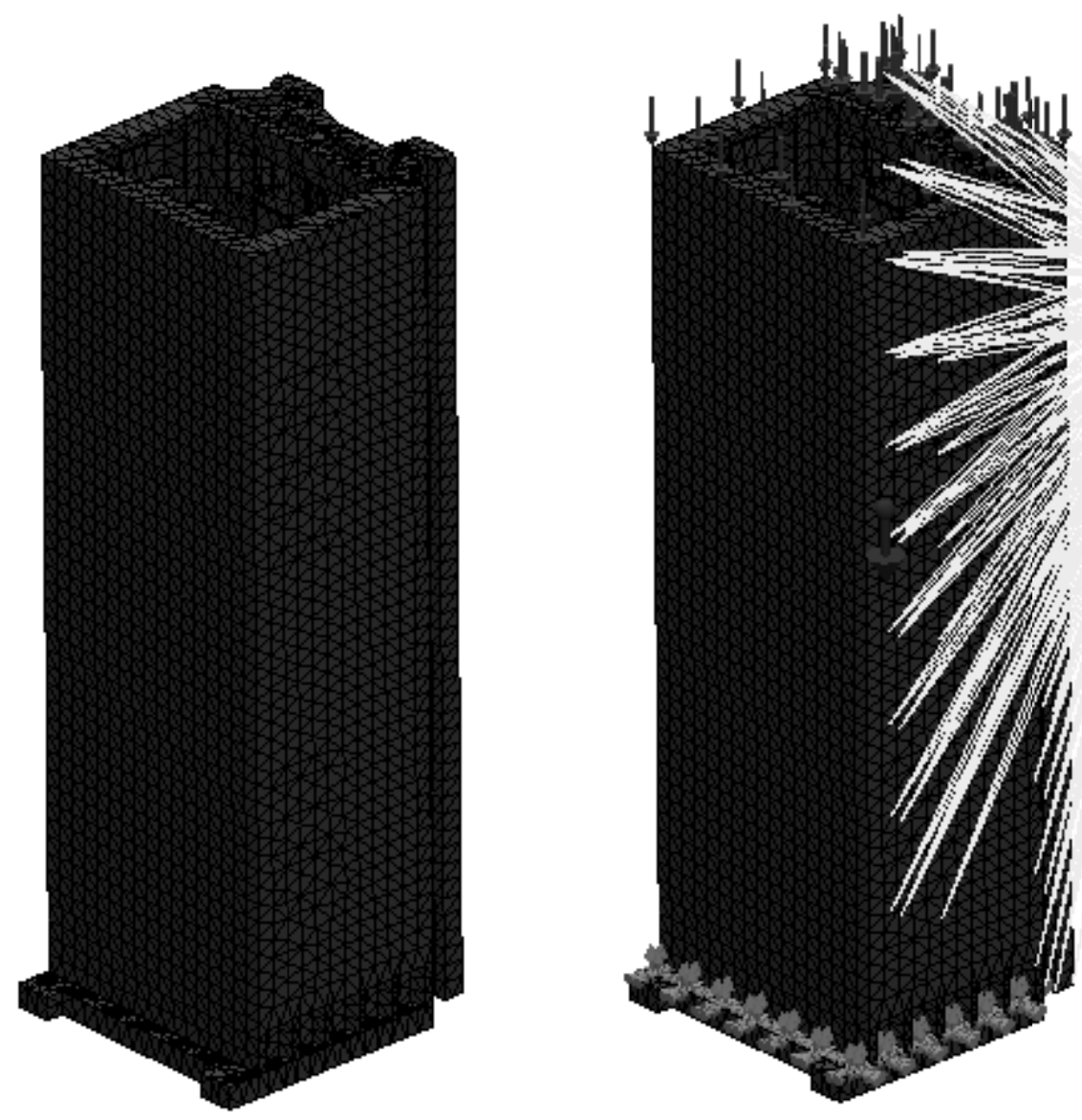

Figure 4. Column FEA model
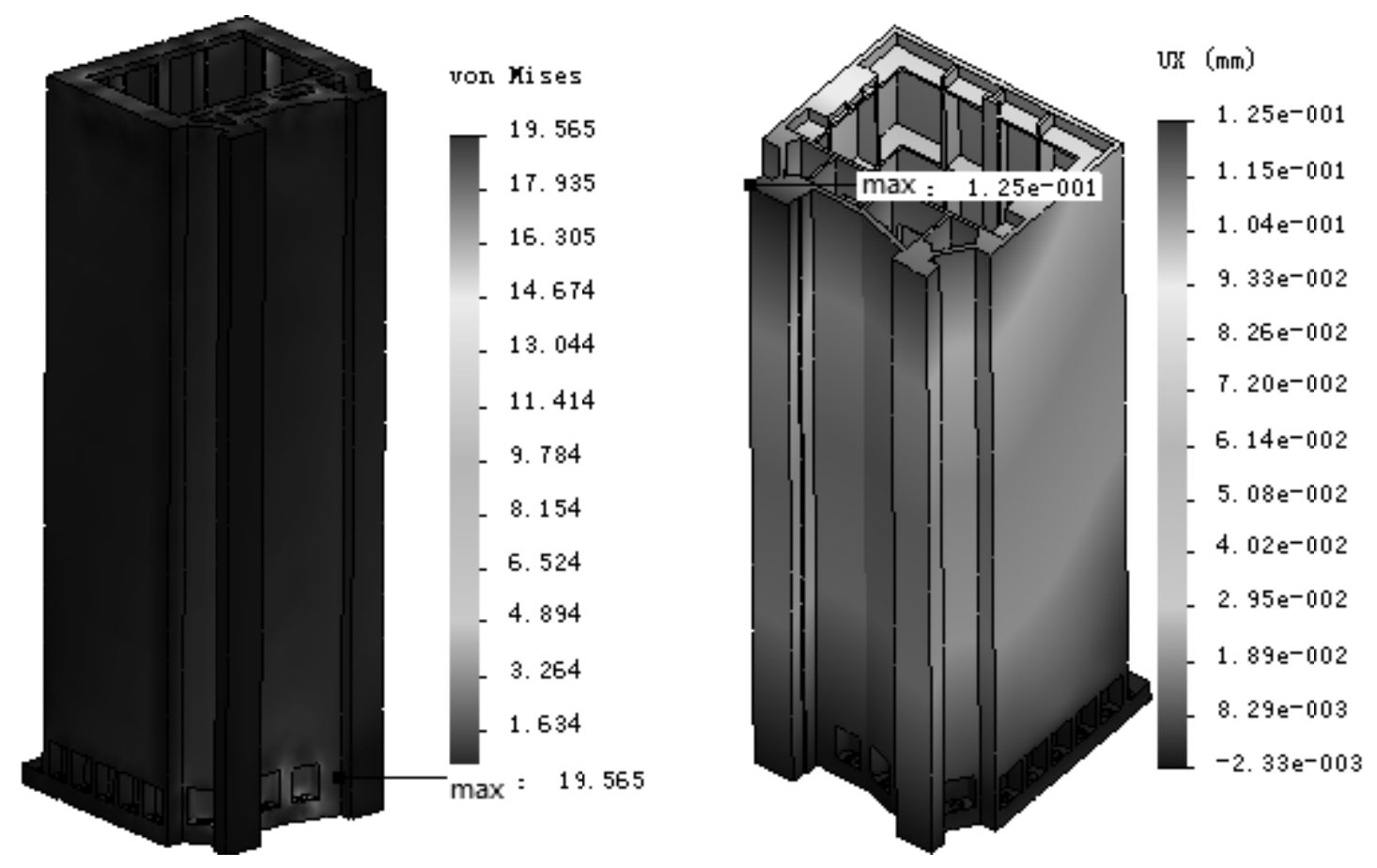

Figure 5. Working stress of the column

Figure 6. The displacement of the column(X direction) 


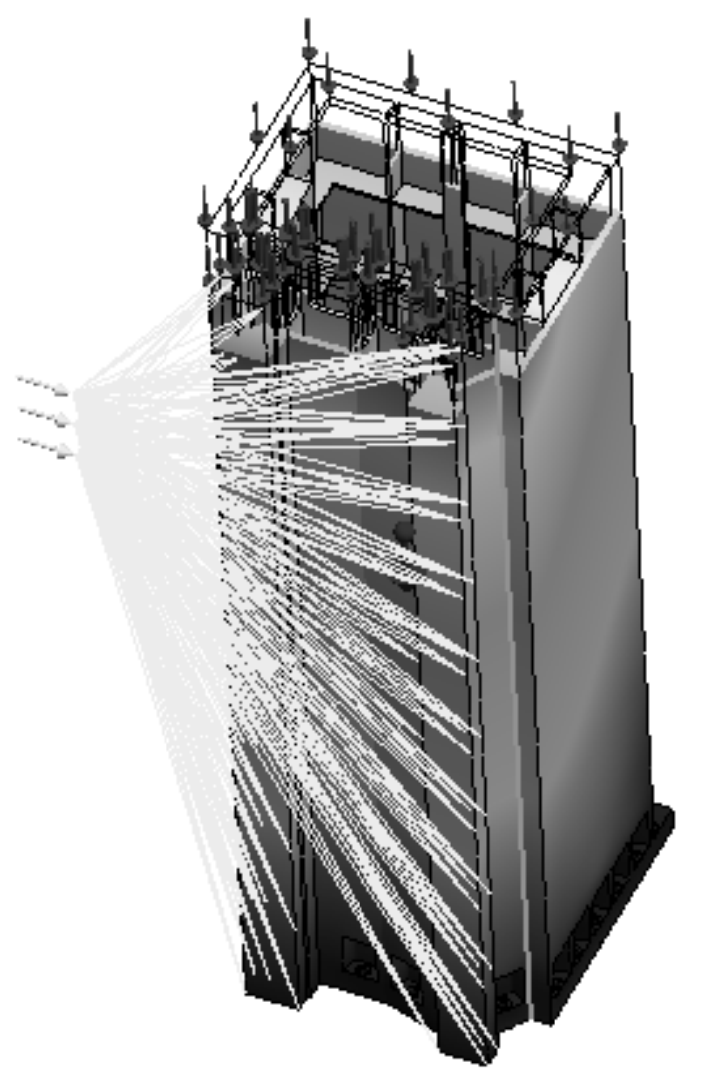

Figure 7. Rib thickness optimization

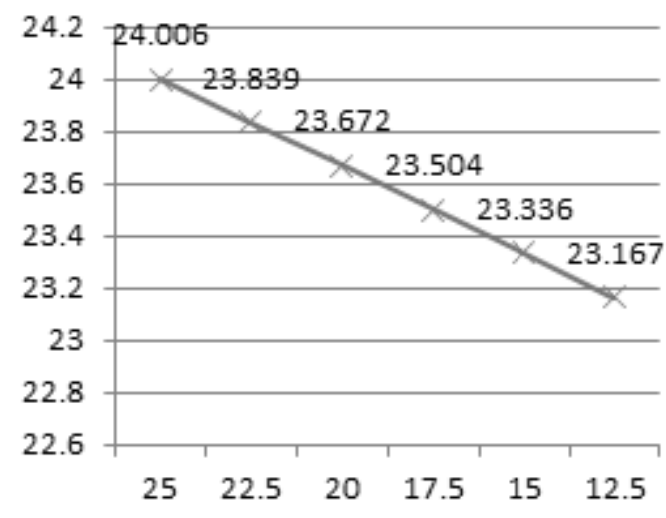

(a)

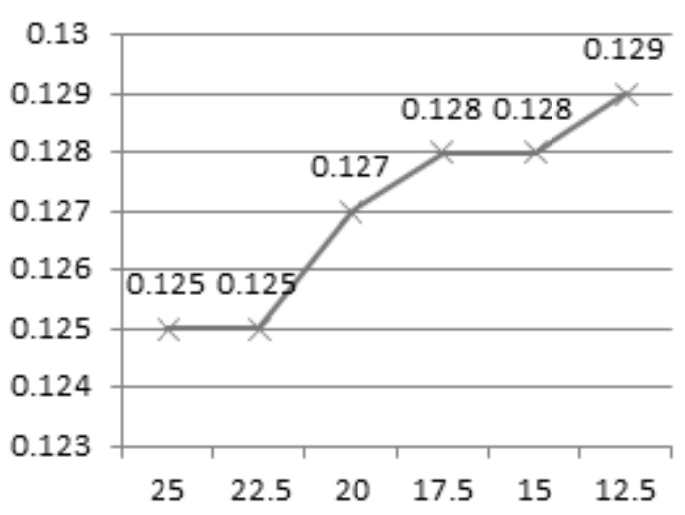

(b)

(a) Relationship between column weight and rib thickness

(b) Relationship between column displacement and rib thickness

Figure 8. 


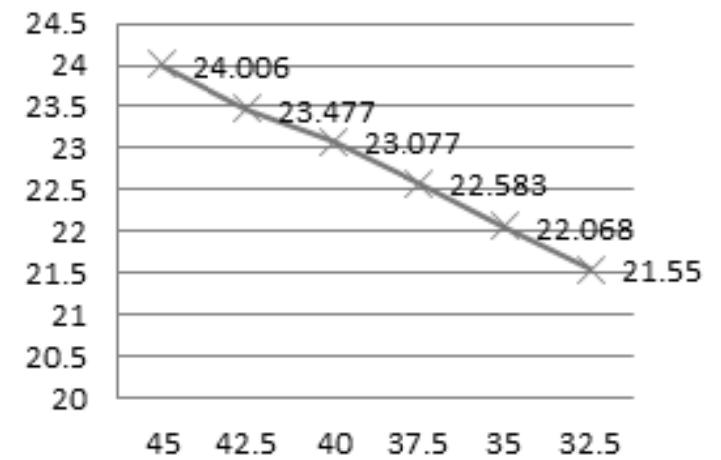

(a)

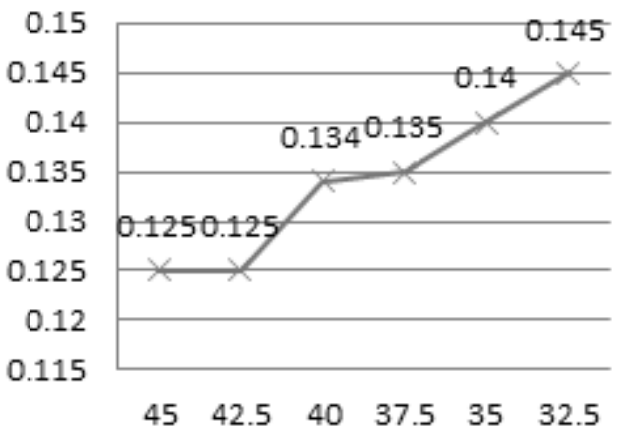

(b)

(a) Relationship between column weight and column thickness

(b) Relationship between column displacement and column thickness

Figure 9.

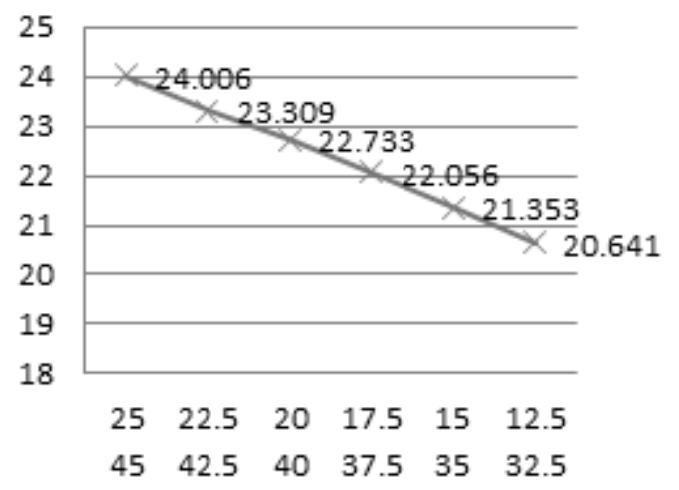

(a)

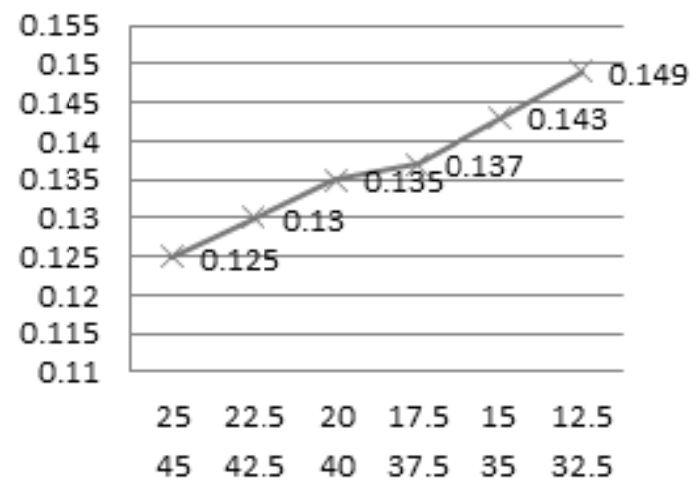

(b)

(a) Relationship between column weight and column thickness, rib thickness

(b) Relationship between column displacement and column thickness, rib thickness

Figure 10. 